\title{
Plasma Glucose Changes in Diabetics During Ramadan Fasting
}

Saud F. Al-Fayez, M.B.CH.B., M.R.C.P. (UK), Yousef A. Khogheer, F.A. Medicine,

Mansour I. Sulaiman, B. Sc. Pharm., Ph. D.,

Jeddah, Saudi Arabia.

DOI: http://dx.doi.org/10.5915/20-2-13265

\begin{abstract}
52 diabetic patients (32 non-insulin-dependent and 20 insulin-dependent) were studied during Ramadan fasting. In NIDD diabetics, fasting plasma glucose levels increased in 11 out of 19 males and 7 out of 13 females. Mean levels ( \pm SEM) rose from $8.7 \pm 0.5$ to $8.8 \pm 0.7 \mathrm{mmol} / 1$ in males and decreased from $9.18 \pm 0.73$ to 8.38 $\pm 0.72 \mathrm{mmol} / 1$ in females.

In IDD diabetics fasting plasma glucose levels rose in 8 males and 7 females. Mean levels rose from $8.53 \pm 0.7$ to $11.88 \pm 1.16 \mathrm{mmol} / 1$ and from $8.88 \pm 0.8$ to $10.25 \pm 1.4 \mathrm{mmol} / 1$ in males and females respectively.

These results were only significant for male IDD diabetics $(P<0.05)$. No correlation was found between changes in fasting plasma glucose levels and body weight.

The possible mechanisms and implications of the trend for fasting plasma glucose levels to rise during Ramadan have been discussed.
\end{abstract}

Key words: Muslim fasting, diabetes, glucose level, body weight

Muslim fasting is characterized by periodic abstinence from food and water from sunrise to sunset and free access to both at night. ' Diabetics, as patients with a chronic disease, may be exempted from fasting, but, as one of the five pillars of Islam, many diabetic patients insist on it. In the meantime, while some physicians advise diabetics against fasting ${ }^{2,3}$, others believe that they can tolerate $\mathrm{it}^{4}{ }^{5}$.

This work was designed to study the effects of Ramadan fasting on the fasting plasma glucose levels of diabetic patients.

\section{Subject and Methods}

52 diabetic patients attending the general Medical Clinics at King Abdulaziz University Hospital during the lunar months of Ramadan (May/June 1985) participated in this study. All patients who insisted on fasting during Ramadan were asked to co-operate. The purpose of the study was explained and a verbal consent was given by each patient. The fasting period was from 04:00 hours to 18:00 hours. Patients were

From the Departments of Medicine and Pharmacology King Abdulaziz University

Jeddah, Saudi Arabia

Reprint requests: Dr. Saud F. Al-Fayez

Department of Medicine

King Abdulaziz University Hospital

P.O. Box 6615

Jeddah 21452, Saudi Arabia left on their usual calorie restricted diets taken in two main meals at 18:00 hours and 03:00 hours.

All diabetics, both non-insulin dependent (NIDD) and insulin-dependent (IDD):

- had their usual dose of insulin or oral hypoglycemic drug given before meals at 18:00 and 03:00 hours.

- had their fasting plasma glucose measured once a week between 08:00 and 12:00 hours for 3 weeks before beginning Ramadan fasting. The mean of these three values for each patient was calculated.

- had their plasma glucose measured once a week during Ramadan between 11:00 and 12:00 hours (i.e. after the same period of fasting as before Ramadan), and the mean of the four values was calculated. Plasma glucose was measured by Beckman Model 42, clinical analyzer and are reported in SI units.

- were weighed at the beginning and at the end of Ramadan, in light clothing, without shoes and using the same scales.

- were asked to report to the Clinic immediately on feeling faint or dizzy.

Statistical analysis was performed with paired t-test, with the level of significance set at $P<0.5$. The correlation between plasma glucose levels and body weight changes was calculated. Results are given as means \pm SEM.

\section{Results}

All diabetic patients participating in the trial were 
able to complete fasting. None of the patients reported symptoms of hypoglycemia.

\section{Non-insulin Dependent Diabetics}

The fasting plasma glucose levels increased in 11 males and 7 females during the fasting period. In males the mean values rose from $8.7 \pm 0.5$ to $8.8 \pm$ $0.7 \mathrm{mmol}$, while in females the values decreased from $9.18 \pm 0.73$ to $8.38 \pm 0.72 \mathrm{mmol} / 1$. These results were not statistically significant $(\mathrm{P}>.05)$. The body weight increased in 9 males and 6 females during Ramadan. In all males, the mean body weight decreased from $79.4 \pm 2.83$ to $79.1 \pm 2.84 \mathrm{Kgm}$ and in females, from $68.1 \pm 2.76$ to $67.7 \pm 2.57 \mathrm{Kgm}$. The correlations between fasting plasma glucose levels and body weight changes during the fasting period in males and females were not statistically significant $(r=0.16$ and -0.3$)$ respectively.

\section{Insulin-dependent Diabetics}

Fasting plasma glucose levels in this group rose during the fasting period in 8 males and 7 females. In all males, mean levels increased from $8.53 \pm 0.7$ to $11.88 \pm 1.16 \mathrm{mmol} / 1$ and from $8.88 \pm 0.8$ to 10.25 $\pm 1.5 \mathrm{mmol} / 1$ in females. The result was statistically significant for males only $(\mathrm{P}<0.05)$.

The body weight decreased in 5 males and 7 females during the fasting period. It decreased from $60.77 \pm 3.42$ to $60.35 \pm 3.37 \mathrm{Kgm}$ in females and from $62.59 \pm 3.1$ to $61.16 \pm 3.42 \mathrm{Kgm}$ in males. These results were not statistically significant.

The correlation between the changes in fasting plasma glucose levels and body weight were $r=$ -0.34 , and $r=0.45$ for males and females respectively. Again, these correlations did not reach statistical significance.

\section{Discussion}

Although the expected danger for diabetics who fast during Ramadan would be hypoglycemia, none of our patients reported to the clinic because of its symptoms and none had to break their fast. On the contrary, although the difference between fasting plasma glucose levels in diabetics was not statistically significant except in male IDD diabetics, there was a trend for fasting plasma glucose levels to rise during the fasting period.

This trend is unlikely to be simply due to relaxation with diet during Ramadan (when more carbohydrates are usually consumed), in view of the lack of correlation between changes in fasting plasma glucose and body weight. Moreover, our patients claimed adherence to their dietary measures.

In insulin-dependent diabetics, the release of hormones like catecholemines, glucagon, cortisol and growth hormone in response to hypoglycemia ${ }^{5,7,8}$ may have a role in this finding. Interestingly, Santiago et $\mathrm{al}^{8}$ noticed that neither the threshold for these counterregulatory mechanisms nor its magnitude were determined by a certain blood glucose level or the rate of blood glucose decline. Moreover, gluconeogenesis may be enhanced by insulin deficiency in IDD patients $s^{9,10}$ and by fasting ${ }^{11}$. The combination of these two factors would be expected to lead to marked hyperglycemia.

In non-insulin depdendnt diabetics, fasting was reported to reduce insulin release $\mathrm{e}^{12,13}$ which would worsen hyperglycemia.

Despite the controversy about the role of strict control in preventing or delaying diabetic complications, many studies support its role ${ }^{14,15,16,17}$. We appreciate that the measurement of fasting blood glucose levels in our study is not enought to assess the state of diabetic control and that none of our patients came to immediate harm, but the trend of plasma glucose levels to be higher is worrysome. Furthermore, the fact that as a lunar month, Ramadan may come at any time of the calendar year, may prolong the fasting period to 18 or 20 hours during summer, especially in the polar region'. This makes diabetic control even more difficult. However, patients with NIDD controlled on diet only, should benefit from this type of fast if weight reduction is achieved.

In conclusion, diabetic patients may manage the Ramadan fast, but plasma glucose levels may be higher during the fast. This observation calls for more attention to the state of diabetic control during Ramadan.

\section{References}

1. Sakr A. Fasting in Islam. J Am Dietet A. 1975;67:17.

2. Baguet R. Les glycemies due Ramadan. Maroc Medical. 1966;45:497.

3. Barber S G, Fairweather S, Wright A D, Fitzgerald M G and Malins J M. Muslim Ramadan and diabetes mellitus. Br Med J 1979;281:46.

4. Davidson J C. Muslim Ramadan and diabetes mellitus. Br Med J. 1979;281:1511.

5. Ebbing R N. Muslims, Ramadan and diabetes mellitus. Br Med J. 1979;281:333.

6. Garber A J, Cryer P E, Santiago J V, Haymond M W, Pagliara A S and Kipnis D M. The role of adrenergic mechanisms in the substrate and hormonal response to insulin-induced hypoglycemia in man. J Clin Invest. 1976;58:7.

7. Gerich J, Davis J, Lorenzi M, Rizza R, Bohannon $\mathrm{N}$, et al. Hormonal mechanisms of recovery from insulin-induced hypoglycemia in man. Am J Physiol. 1979;236:E 380.

8. Santiago J V, Clarke W L, Shah S D. Epinephrine, norepinephrine, glucagon and growth hormone release in association with physiological decrements in the plasma glucose concentration in normal and diabetic man. J Clin Endocrinol Metab. 1980;51:877 
9. Chochinov R H, Bowen H F, Moorhouse J A. Circulating alanine disposal in diabetes mellitus. Diabetes. 1978;27:420.

10. Hall S E H, Foster D M, Berman M. Normal glucose; alanine relationships and their changes in untreated and treated diabetic patients. Diabetes. 1978;27:461

11. Chiasson J L, Atkinson R L, Cherrington A D, Keller U, Sinclair Smith B C, et al. Effects of fasting on gluconeogenesis from alanine in nondiabetic man. Diabetes. 1979;28:56.

12. Genuth S. Supplemented fasting in the treatment of obesity and diabetes. Am J Clin Nut. 1979;32:2579.

13. Vessby B, Boberg M, Karlstrom B, Lithell $\mathrm{H}$ and Werner I. Improved metabolic control after supplemented fasting in over-weight type II diabetic patients. Acta Med Scand. 1984;216:67.
14. Johnsson E. Retinopathy and nephropathy in diabetes mellitus. Comparison of the effect of two forms of treatment. Diabetes. 1960;9:1.

15. Miki E, Kuzuya, T, Nakas K. Frequency, degree and progression with time of proteinuria in diabetic patients. Lancet. 1978;1:922.

16. Pirat J. Diabetes mellitus and its degenerative complications: A prospective study of 4400 patients observed between 1947 and 1973. Diabetic Care. 1978;1:168.

17. White N H, Waltman S R, Krupin T, Santiago J V. Reversal of abnormalities in ocular fluorophotometry in insulin-dependent diabetes after five to nine months of improved metabolic control. Diabetes. 1982;31:80. 